\title{
O processo de trabal ho em saúde e a produção do cuidado em uma unidade de saúde da família: limites ao acolhimento e reflexos no serviço de emergência
}

\author{
The work process in health and the production of care \\ in a Family Health Unit: limits to the reception \\ and reflections on the emergency service
}

Delba M achado Barros ${ }^{1}$

M arilene de Castilho Sá ${ }^{2}$
${ }^{1}$ Secretaria M unicipal de SaúdedeQuissamã. Rua CondedeAraruama 425, Centro. 28735-000 Quissamã RJ.

delbabarrosrj@gmail.com

${ }^{2}$ Departamento de

Administração e

Planejamento em Saúde,

Escola Nacional deSaúde

Pública Sergio Arouca,

Fundação Oswaldo Cruz.
Abstract This study examines the work process of a Family $\mathrm{H}$ ealth U nity (USF) in a small municipality, inland the state of Rio de Janeiro. We would like to start with the question of what is causing the population registered in a family health program to look for the Emergency Service (SE) of a General Hospital. Semi-structured individual interviews were conducted with doctors who worked on duty and users in the Emergency Serviceand group interviews with users of a Family $\mathrm{H}$ ealth $U$ nit and its staff. In addition, information was also collected by participant observation. Thetheoretical fields of $\mathrm{H}$ eal th $\mathrm{M}$ anagement and Psycho-sociology were the grounds of this research. It was concluded that the "modus operandi" of the USF, the geographical and organizational accessibility, and the technological apparatus of theSE ended up leading the population to seek the General Hospital emergency service of the municipality mentioned in this study in acute situations of suffering and distress.

Key words Family health, Production of care, Work process in health, Emergency service
Resumo Esse estudo examina o processo de trabalho deuma unidade de saúdeda família (USF), em um município de pequeno porte, no interior do Estado do Rio de Janeiro. Parte-se da pergunta sobreo que estaria levando a população adscrita a uma USF ao serviço de emergência (SE) de um hospital geral. Foram feitasentrevistas individuais semiestruturadas com plantonistas e usuários no SE e em grupo com os usuários e com a equipe de saúde da família, na U SF, além de observação participante. 0 campo teórico da gestão em saúde e da psicossociologia embasaram essa pesquisa. Concluiu-se que o modus operandi da USF, a acessi bilidade geográfica eorganizacional eo aparato tecnológico do SE acabam por conduzir a população a procurar o serviço de emergência do hospital geral do município estudado em situações agudas de sofrimentos e angústias.

Palavras-chave Saúde da família, Produção do cuidado, Processo de trabalho em saúde, Serviço de emergência 
Introdução

A redução do número de atendimentos ambulatoriais nas emergências hospitalares é um dos resultados esperados com a implantação da Estratégia da Saúde da Família1,2. Se, por um lado, a literatura do Ministério da Saúde sobre saúde da família relata que, em média, $85 \%$ das demandas e ações por serviços de saúde podem ser resolvidos no primeiro nível de atenção, por outro lado, a maior parte dos atendimentos realizados nos serviços de urgência/emergência é de situações ambulatoriais passíveis de serem atendidas nas unidades primárias de saúde.

Embora haja definições técnicas para urgência/emergência, parte-se do pressuposto de que a população usuária possui uma definição própria que a leva a procurar por este serviço, o que será um dos objetos de análise neste artigo. Do ponto devista da gestão, procurar o SE em situações que não se caracterizam como emergências éum problema. Entretanto, para o sujeito "doente", pode ser uma "solução", pela possibilidade de alívio mais rápido de seu sofrimento.

De acordo com o parâmetro de cobertura assistencial, da Portaria $n^{0} 1.101^{3}$, a quantidade de consultas básicas de urgência e consultas de urgência pré-hospitalar e trauma estimada no município estudado, em 2004, 2005 e2006, eram de 6.740, 7.057 e 7.221, respectivamente, considerando o total de população de 14.977 hab., 15.683 hab. e 16.046 hab., conforme dados do IBGE. Entretanto, os atendimentos médicos computados pelo SE foram $36.036 \mathrm{em}$ 2004, 24.096 em 2005 e 38.074 em 2006.

Os plantonistas médicos relataram queo percentual deatendimentos deemergência/urgência émínimo duranteo plantão de 24 horas. Osproblemas de saúde elencados por eles como de maior incidência no SE, foram: hipertensão, gripe, diarréia, lombalgia, cefaléia, hiperglicemia, doenças respiratórias (rinite alérgica, asma, viroses) e distúrbio neurovegetativo.

Com os números ora apresentados, observamos que, embora tenha havido uma redução de atendimentos em 2005, o volume de atendimentos no SE ainda é expressivo, tendo em vista o tamanho da população e a cobertura assistencial pela Estratégia deSaúde da Família, em 2004, de $83 \%$, em 2005 , de $84 \%$ e, em 2006 , de $90 \%$, de acordo com o DATASUS.

Considerando que a Estratégia da Saúde da Família tem como baseo acolhimento, o vínculo e a responsabilização, a questão que se coloca diante da quantidade de atendimentos no SE é:
"O que faz a população aportar em situações consideradas ambulatoriais no SE, tendo cobertura assistencial por uma equipe de saúde da família?" Entender o porquê da demanda na porta do serviço deurgência/emergência poderá subsidiar a reorganização do sistema de saúde local.

\section{M etodologia}

Trata-se de um estudo de caso que teve como referenciais teóricos metodológicos as contribuições de autores brasileiros do campo da gestão em saúde ${ }^{47}$, para discutir a produção do cuidado em saúde, e de autores franceses do campo da psicossociologia ${ }^{8,9}$ e da psicodinâmica do trabaIho ${ }^{10}$ para discutir os aspectos subjetivos e os fenômenos sociais conscientes e inconscientes que atravessam o processo de trabalho e as organizações de saúde.

As categorias utilizadas nesse estudo foram acolhimento, vínculo eresponsabilização, na perspectiva de Franco eM erhy ${ }^{4}$, que as definem como: Acolhimento, em primeiro lugar como a possibilidade de universalizar o acesso, abrir as portas da U nidadea todos os usuários que dela necessitarem. E ainda como a escuta qualificada do usuário, o compromisso com a resolução do seu problema de saúde, dar-Ihe sempre uma resposta positiva e encaminhamentos seguros quando necessários. 0 Vínculo baseia-se no estabelecimento de referências dos usuários a uma dada equipe de trabalhadores, ea responsabilização destes para com aqueles, no que diz respeito à produção do cuidado.

$\mathrm{Na}$ perspectiva psicossociológica, a apreensão do sentido e o significado são centrais, mas apresenta algumas especificidades e diferenciações. Uma delas é a importância da participação do inconsciente nos processos de conhecimento ${ }^{11}$. 0 imaginário enquanto princípio fundador da sociedade e enquanto el emento que origina a vida social e todas as representações que são geradas a partir daí ${ }^{12}$ é relevante para a compreensão da dinâmica do processo de trabalho, pois para apreender o trabalho em sua complexidade, énecessário entendêlo e explicá lo para além do que pode ser visível e mensurável ${ }^{13}$.

O sofrimento no trabalho e a produção do sentido na vida da organização também são aspectos importantes na análise psicossociológica e na psicodinâmica do trabal ho.

Trata-se, sobretudo, de um trabal ho de construção de sentido como o resultado de um diálogo, através do qual o pesquisador provoca, por sua presença e por suas palavras, os atores so- 
ciais/sujeitos a falar e a discutir a respeito de suas experiências ou daquilo que elas possam evocar ou significar para eles ${ }^{12}$. Portanto, é uma construção sempre provisória.

Para a coleta de dados no SE, utilizamos as seguintes técnicas: análise dos 7.048 boletins de atendimentosnos meses de março eabril de 2006 e entrevistas semiestruturadas com cinco plantonistas e dez usuários, nos diasúteis da semana, quando a população mais procura por atendimento. NaUSF, utilizamos: análise de documentos oficiais; observação participante da dinâmica de funcionamento; acompanhamento longitudinal de dois usuários (um adulto e uma criança) eentrevistas semiestruturadas em grupo, duas com a equipe de saúde da família e uma com os usuários deste serviço.

Estamos denominando de acompanhamento longitudinal a atividade, com o consentimento livre e esclarecido do usuário, de permanecer ao seu lado como "sombra" em toda trajetória de atendimento na USF.

Considerando que havia uma demanda expressiva, computada nos boletins de aten dimentos do SE, das populações adscritas a todas as USF, optamos nesse estudo por uma USF no centro urbano, com uma equipe que tinha uma trajetória de trabalho de pelo menos um ano sem alteração de seus membros. A saída do campo se deu pela repetição do conteúdo das entrevistas e das observações do cotidiano sobre as questões da pesquisa.

As entrevistas com os usuários e trabalhadores de saúde somaram quinze horas e as observações totalizaram oitenta horas.

A pesquisa atendeu a Resolução n 196/96 do Conselho Nacional de Saúde. Foi desenvolvida no período de abril a novembro de 2006.

\section{A rede assistencial existente}

Em 2006, a rede pública de saúde no município estudado era composta por nove equipes de saúde da família em dez unidades primárias de saúde, isto porque uma equipe é responsável por duas USF em função do número de pessoas adscritas, um centro deespecialidades com dezoito especial idades médicas, além do serviço de fisioterapia e serviço social, um Centro deAten ção Psicossocial, um ambulatório ampliado de saúde mental e um hospital geral com 54 leitos. Acoplado ao hospital, existe um SE com laboratório e raio x 24 horas.

Desde 2001, a Estratégia de Saúde da Família tem sido o modelo adotado para a organização da atenção primária, conforme apontado no Plano M unicipal de Saúde. As equipes de saúde da família possuem um médico, um enfermeiro, um técnico de enfermagem, agente comunitário de saúde (ACS) de acordo com o número de famílias, um agente administrativo e um auxiliar de serviços gerais. As USF maiores possuem ainda uma recepcionista e mais um técnico de enfermagem. A maior USF possui 913 famílias adscritas, totalizando 3.377 residentes em seu território de abrangência, o que está dentro do recomendado pelo M inistério da Saúde $e^{1,2}$.

Todas as USF possuem dentistas em dois ou três dias da semana e nutricionistas, em um ou dois turnos por semana, conforme o contingente populacional adscrito a USF. Há também duas equipes de saúde bucal em duas USF centrais e dois fisioterapeutas em duas USF mais distantes do centro urbano, em al guns dias da semana. Em todas as USF, há um posto volante de coleta de exames de patologia clínica uma vez por semanae são dispensados, diariamente, medicamentos da farmácia básica. Os medicamentos das especialidades são distribuídos no centro de especialidades e, no CAPS, somente para os usuários com transtorno mental inseridos no serviço.

São feitos no município ultrassonografias, eletrocardiogramas, ecocardiogramas, testes ergométricos, além do raio $x$ simples. Os demais exames de média e alta complexidade são realizados nos municípios vizinhos.

A rede de saúde instalada está para além dos parâmetros da cobertura assistencial preconizados pela Portaria ${ }^{\circ} 1.101$, considerando que eleé referênciana Programação Pactuada da Assistência à Saúde para apenas um outro município de sua região, para procedimentos de fisioterapia.

\section{O processo de trabalho} e a produção do cuidado

A USF tem uma forma de agendamento de consultas e exames laboratoriais com abertura da marcação no primeiro dia útil da segunda quinzena do mês e fechamento ao completar a capacidade de agendamento estipulada. $N$ as agendas de cada membro da equipe, há turnos de trabaIho destinados à realização de reuniões de equipe, visitas domiciliares e atividades de educação permanente, não havendo atendimento de pacientes nesses horários.

A recepção é que define 0 acesso do usuário que procura o serviço nas condições agudas ou crônicas não agendadas. A recepcionista defineo 
setor como um "pára-raios", por que está aberta ao contato com o público e dá destino a demanda do usuário. Embora a recepção seja o lugar das "descargas emocionais" dos usuários, é um lugar ocupado por vários trabal hadores de saúde, exceto o médico e a enfermeira, na falta da recepcionista, por motivos particulares ou deserviço, o que nos leva a pensar que esses trabaIhadores, para se protegerem contra o sofrimento e mal-estar gerado no exercício cotidiano de entrar em contato com a demanda enegar 0 acesso da população ao serviço, adotam o rodízio como estratégia defensiva coletiva ${ }^{10}$. Assim, paradoxalmente, apesar de ser um lugar "ocupado" fisicamente por muitos, é difícil de ser ocupado de fato no sentido de assumir a responsabilidade pelo cuidado do usuário.

A observação comparativa entre o SE ea USF mostra que o SE possui menos obstáculos organizacionais de acesso ao usuário do que a USF.

No posto (USF) não tem médico todos os dias, conforme aponta uma usuária no SE, confirmado pelo cronograma de agendamento da USF. Já - SE possui por plantão dois clínicos, dois pediatras e um obstetra, além de um obstetra e um anestesista de sobreaviso.

Por sua vez, o SE funciona 24 horas todos os dias dasemana, diferentementedaUSF, quefunciona somente em dias úteis da semana, de $8 \mathrm{~h}$ às $11 \mathrm{~h} 30 \mathrm{~min}$ e das $13 \mathrm{~h} 30 \mathrm{~min}$ às $17 \mathrm{~h}$. Há um dia fixo da semana em queéfeito um turno deatendimento médico e de enfermagem das $17 \mathrm{~h}$ às $20 \mathrm{~h}$.

O SE tem disponível exames de laboratório e raio $x$, podendo ser acionado a pedido do plantonista em qualquer momento com entrega do resultado em tempo hábil para definição da conduta médica. Se necessário, o usuário fica em observação ou interna no próprio ou em outro hospital, conforme o problema de saúde apresentado. Portanto, o usuário tem garantida a continuidade da assistência caso precise de um maior aparato tecnológico.

N ormalmente, os serviços de pronto-socorro, especialmente nas grandes cidades, são retratados pela mídia como desumanos, com longas filas de pessoas aguardando, muitas vezes em pé, com macas em corredores, etc. Essa não é a realidade do SE do município estudado. 0 usuário aguarda pelo atendimento em um ambiente climatizado, com cadeiras estofadas, bebedouro e televisão.

Sá, ao discutir a demanda na porta de entrada de um hospital de emergência no município do Rio de Janeiro, considera que a demanda por cuidado não se restringe aos cuidados médicos tradicionais, uma vez que nela estão implicados problemas de toda ordem, o que corrobora que muitos dos problemas atendidos no SE poderiam ser acolhidos nas USF. A intensificação dos processos de exclusão social e a violência urbana, 0 empobrecimento da população, a precarização das relações de trabalho, o desemprego, a fragilidade crescente dos víncul os sociais e dos mecanismos de solidariedade e a incapacidade geral de resposta das políticas públicas a esses problemas [...] acaba por desaguar, na porta de entrada dos serviços de saúde, problemas tão graves quanto diversos ${ }^{14}$.

De um lado, os usuários decidem o tempo de espera que podem tolerar para serem atendidos ea partir disso dirigem suas demandas aos serviços de saúde conhecidos: Eu procuro o posto de saúde em consultas marcadas, as que podem esperar. Aqui, no meu caso, ele está com febre, eu não posso esperar consulta daqui a quinze, vinte dias. E aqui, em quarenta minutos, se consegue ser atendido (usuária no SE).

De outro, os trabalhadores de saúde descrevem a espera como algo inerente ao serviço público de saúde e entendem que cabe ao usuário "aguardar" pelo tempo estabelecido pela organização: Se eu digo para o paciente que ele vai esperar quinze dias para fazer o exame, el e diz: "nossa, atélá, eu já morri". Agora, ele está fazendo rotina. Para mim, é difícil atender uma urgência que não está escrito urgente. E para ele, de esperar quinze dias, porque elenão quer esperar quinze dias. $M$ as o PSF trabalha com o tempo. As pessoas têm urgência para tudo. Tudo deles é para ontem. PSF não é para ontem (recepcionista da USF).

0 trabalhador de saúde considera que é possível esperar por atendimento agendado, talvez porque esteja vendo a situação problema pela ótica da organização do serviço enão da demanda do usuário. Oliveira chama aten ção queo tempo que o usuário reclama não é, necessariamente, o cronológico: Pode não se limitar ao aspecto quantitativo do tempo medido em horas ou em dias de espera, mas a outros critérios mais subjetivos, que são próprios do usuário e que estão vinculados muito maisà dimensão ou complexi dadeatribuída por ele à sua experiência de sofrimento do que a qualquer outra coisa ${ }^{15}$.

Os depoimentos acima são emblemáticos das contradições e desafios da Estratégia de Saúde da Família. Por um lado, é possível destacar a dificuldade dos trabalhadores de saúde da família em acolher o sofrimento dos usuários e uma visão dicotômica entre promoção e assistência. Para a médica de família, o modelo do PSF é o modelo que trabal ha com a prevenção e promoção 
e el es [a comunidade] ainda não entenderam isso. Elesacham queo médico épara ser procurado quando el es estão doentes enão quando estão com saúde para poder fazer um acompanhamento, para receber orientações, para tomar determinados medicamentos quando precisam, para poder permane cer com saúde.

Por outro, traduzem também a contradição entre os "tempos lentos" necessários à promoção e à assistência integral à saúde e os "tempos rápidos" ou o "domínio da urgência" como modalidade predominante de subjetivação e sociabilidade na sociedade contemporânea ${ }^{16-18}$.

A população "aprende" na relação com os serviços de saúde queémaisfácil procurar 0 atendimento no SE quando precisa ter uma solução para seu "problema" de forma mais rápida ou o acesso a um determinado exame. A USF estudada dificilmente viabiliza atendimento ao usuário quando ele não está agendado e tampouco garante seu acompanhamento quando orientado a buscar assistência em outros serviços de saúde. Para exemplificar uma das situações observadas na porta de entrada da USF, citamos a situação deuma mãe que chegou à unidade dizendo quea filha estava com febre e com crise de bronquite. A recepcionista pediu para a mãe retornar no dia seguinte à tarde ou procurar o hospital. A mãe retrucou que, no dia seguinte, no turno da tarde, a criança faltaria a mais um dia de aula. A recepcionista disse: Se a senhora achar melhor, procure o hospital. E acrescentou: Se a senhora ficar contente com 0 atendimento do hospital, a senhora não precisa vir aqui, caso contrário a senhora pode vir amanhã.

É frequente, entre os trabalhadores, as referências aos usuários como desinformados, mal acostumados, entre outros predicativos, geralmente pejorativos, por não fazer o percurso definido pela organização do sistema, mas sim 0 percurso em que se sentem atendidos em suas demandas.

A ideia dequeo usuário não entendea filosofia da saúde da família e que não distinguea diferença entre emergência e ambulatório é uma retórica de quem trabalha nos serviços de saúde desse município efaz uma leitura racional, isto é, tecnocrática da trajetória do usuário pelo sistema: Eu acho quetem paciente que não quer entender o que éo PSF porque não quer entender mesmo. Porque não é falta de explicar, orientar, de falar como funciona, como é. Tem gente quejá está acostumado com aquele outro tipo de atendimento. Ainda não se acostumou como o PSF funciona (ACS).
O que observamos, no entanto, éque o usuário quer é ser atendido e para tal ele busca os caminhos que são do seu conhecimento e os serviços que lhe dão acesso ao atendimento de sua demanda ${ }^{46,64,15}$. Portanto, não se trata de explicar para o usuário que o SE não éo local adequado para "cuidar da saúde" dele, enquanto a USF não for capaz de acolher e dar um destino adequado às demandas em um tempo capaz de ser tolerado pelo usuário.

Portanto, a forma de funcionamento do sistema de saúde acaba por reforçar a crença popular que apenas no hospital se encontram as condições para alívio do sofrimento ${ }^{19}$. Não somente por que - SE acaba por atender a demanda do usuário como também a USF não conseguiu fazer a virada do modelo assistencial na direção de uma maior articulação entre promoção eassistência, açõesindividuais e coletivas, procedimentos e cuidado.

Para alguns trabalhadores e para a população, a equipe de saúde da família poderia ser acrescida de outros médicos, como, por exemplo, pediatra, ginecologista eaté geriatra. 0 geriatra foi sugerido com a al egação de que, na área da USF em estudo, têm muitos idosos acamados Essa necessidade [de geriatra] até eu mesmo sinto, porque as pessoas idosas precisam de tratamento especiais que eu não estou, vamos dizer assim, capacitada clinicamente para dar essa assistência integral que eles precisam. Eu gostaria que tivesse um geriatra para poder fazer esses acompanhamentos. Tem um geriatra no centro de referência, mas nem todo idoso pode ir (médica de família).

A angústia de não saber cuidar da população em todo o ciclo da vida, observada nos depoimentos de alguns profissionais, põe em xeque 0 ideário de potência da equipe de saúde da família: Porque é aquela história, o médico do PSF é 0 clínico geral que o pessoal falava, quetratava tudo. M as elenão tem aquela obrigação de saber tudo. É tentar abraçar o que dá para fazer, até para evitar o congestionamento do hospital e até do centro de especialidades. Você, como médico de família, você não vai a congresso de cardiologia, de endocrinologia ou de pediatria. Você não vai em todos os congressos, você vai na sua especialidade e o resto é o quevocêtevena faculdade ou o quevocêlêno dia a dia (médico plantonista que trabalha em uma outra USF como médico de família).

A demanda por inclusão de outros médicos soa, então, como falta de confiança na capacidade resolutiva do médico de família. A própria recepção da unidade orienta as mães que solicitam atendimento pediátrico a procurar esse tipo de atendimento no SE. 
A recepcionista observa que "nem todo mundo que vem ao PSF étapado, éignorante", o que deu a entender que os "mais esclarecidos" demandam para as especialidades médicas a resolução dos seus problemas de saúde. Essa trabaIhadora é uma das que questiona o saber do médico generalista com a seguinte argumentação: o PSF não tem dentista; não tem nutricionista; não tem enfermeira; não tem obstetra; porque não pode ter o pediatra?

A angústia de não saber responder a demanda que vem do outro acaba por transferir para outros trabalhadores de saúde ou outros serviços a responsabilidade pelo cuidado, antes mesmo de compreender a demanda. 0 diálogo entre os trabalhadores de saúde da USF indica esses processos. Vejamos o que dizem uma ACS e uma técnica deenfermagem: Tem pacientequeliga para você duas ou três vezes na semana para você ir a casa dele verificar a pressão. N este mês, eu já fui à casa de uma paciente quatro vezes, até agora. É uma paciente complicada, porque ela teve AVC, também tem depressão, então ébom dar um pouco de atenção. M as também tem que cortar. Eu falei: "Quando tiver passando mal, você procura o SE ou você liga para um técnico de enfermagem verificar sua pressão porqueeu não posso me responsabilizar". 0 que acontece se a paciente está realmente passando mal, a gente não pode encaminhar, a gente não pode fazer nada (ACS).

$\mathrm{N}$ em o técnico. É o médico ou a enfermeira. Eu acho quese ela está passando mal, ela tem que chamar o SE. O u quem tem que acompanhar a visita desse paciente que está passando mal, éa doutora a enfermeira. Eu e a outra técnica de enfermagem não podemos fazer nada. Vou chegar lá, só vou poder conferir a pressão dela e chamar a ambulância. Porque eu não vou poder medicá-la. Não vou poder fazer nada. Só a doutora pode medicar (técnica de enfermagem).

O médico defamíliatambém évisto por vezes como uma imposição do sistema de saúde e uma falta de opção do usuário: Eu, como mãe, eu quero levar meu filho num pediatra. Se você tivesse um filho, você queria levar ele em quem? M as o usuário, não tem o direito de escolher e tem que fazer 0 quea gentequer. A consulta marcada para doutora, dia tal. M as, às vezes, ela não queria isso, queria ir para o pediatra (técnica de enfermagem).

Alguns usuários questionam o médico de família: Eu acho assim, que médico de adulto tem que ser de adulto, médico de criança deve ser de criança (usuária na USF).

Outros usuários acreditam também que pre cisam ter outros especialistas na USF, acham que um único médico é insuficiente: Precisa ter mais médicos no posto. Doutora [médica de família] é clínica geral. Deveria ter mais médico. Por exemplo: eu tenho problema de nervos, deveria ter neurologista aqui, aqui não tem. D outor " $M$ " trabalha lá [centro deespecialidades], para diabéticosenão tem aqui. Tem que procurar lá (usuária na USF).

Esses depoimentos mostram, por um lado, como ainda é supervalorizada, no imaginário social, a especialização médica e o procedimento em saúde centrado na figura deste profissional; por outro lado, é impossível não reconhecer a legitimidade no discurso dos usuários, excluindo o extremo de ter um neurologista na atenção primária, quando demandam um pediatra. Até que ponto o médico e a enfermeira de família conseguem "suprir" o pediatra e o ginecologista excluídos da equipe mínima de saúde da família preconizada pelo M inistério da Saúde, considerando a formação profissional obtida na academia?

O fazer dos trabalhadores de saúde está muito mais voltado para procedimentos (consultas, vacinas, curativos, visitas domiciliares, entre outros) do que para o cuidado, isto é, produção devínculo, acolhimento, autonomia do usuário no cuidado de si, em suma, para as "tecnologias leves" 20.

Há um predomínio na organização do trabalho de consultas e procedimentos individuais e uma dicotomia entre assistência e prevenção, como é possível observar nos agendamentos de consultas, por exemplo. A médica destina sua agenda para atendimentos na clínica geral, pediatria e para hipertensos e diabéticos, enquanto a enfermeira para preventivos, puericultura (crianças saudáveis até um ano), pré natal e planejamento familiar.

Essa divisão do trabal ho enquadraalgunsusuários nos tipos de atendimentos ofertados e provoca o encaminhamento de outros para fora da USF.

Em todas as visitas domiciliares das quais participamos, observamos que a intervenção médica sempre gerava uma prescrição medicamentosa ou encaminhamento para especialista. Jáa enfermeira e os ACS orientavam, ainda que de forma prescritiva, hábitos saudáveis e retorno à USF.

Esses trabalhadores utilizam-se muito mais das "tecnologias leve-duras" do que das tecnologias leves, prevalecendo o cuidado centrado no trabalho morto, isto é, no instrumental técnicocientífico e em exames emedicamento ${ }^{20}$.

Os demais trabalhadores se colocam como coadjuvantes ao serviço e não como corresponsáveis pelo ato de cuidar. A pesar da equipe ser multiprofissional, os trabalhadores de saúde atuam de forma desarticulada e fragmentada. 
A compreensão do acolhimento como inclusão e como uma rede de conversações, visando às possibilidades de atender às necessidades dosusuários, ainda não é generalizada para todos os que trabal ham na rede. A responsabilização pelo cuidado exige o acolhimento e vínculo do usuário.

A preocupação com o vínculo do usuário à USF atravessou as falas dos plantonistas do hospital e usuários, evidenciando a fragilidade ou a inexistência dele: Tem um colega [médico defamília] que é pediatra, eu percebo que a comunidade dele gosta muito dele, el e faz um trabalho legal ali, mas isso é muito particular de pediatra que trabaIha em PSF. 0 pessoal criou o vínculo, ele cultivou isso com a comunidade. Ele é o único colega que ouço o pessoal mais falar (médica plantonista).

Os plantonistas consideram que os usuários, por não terem vínculo com a USF e confiança no médico defamília, principalmente, no atendimento a crianças, procuram 0 atendimento do SE. Por sua vez, a forma pela qual o usuário se sente acolhido no SE também o influencia a retornar a esse serviço. Alguns plantonistas, a depender da relação que estabelecem com o usuário, se responsabilizam pelo cuidado, solicitando o retorno do mesmo em seu plantão.

Essa atitude gera vínculos positivos; entre tanto, riscos de descontinuidade da assistência se não for garantido ao usuário o encaminhamento a um serviço apropriado, depois de realizados os primeiros cuidados necessários.

A equipe desaúde da família, por sua vez, diz que o usuário está acostumado a procurar outros serviços de saúde anteriormente frequentados. Já os usuários destacaram o "apego" ao plantonista como uma das razões pela busca de atendimento no SE.

Interpretamos o apego como a expressão da manifestação do vínculo do usuário com um trabalhador de saúde: Ela nasceu com a doutora $X$. Ela estava deplantão. Ela étão boa. Eu meapeguei. A gente se apega aquele médico que trata bem a gente, o filho da gente. A gente passa a se apegar e todo o remédio que passa dá certinho (usuária no SE para atendimento pediátrico porque o filho estava com nariz entupido ecom dificuldade para respirar e dormir).

Uma vez instal ada essa relação de "apego" com um trabalhador médico que não 0 médico de família, é difícil atrair esse usuário para a USF, conforme relato daACS: Tem pacientequese apega a um médico e só quer ir naquele médico. Você fala para vir a médica da unidadeenão adianta. A gentefala implorando. $\mathrm{N}$ em assim.

Esse apego endereçado a um médico é uma resposta à qualidade do cuidado recebido pelo usuário e pode se verificar no próprio serviço de emergência, no relato deum dos médicos plantonistas: $N$ ão éo certo. M as eu já atendi al guns doentes que eu senti que precisava de uma atenção $x$, $e$ que eles não estavam encontrando e que, às vezes, eu mandava voltar para mim. M as não éo correto. Às vezes acaba quea mãeseidentifica com a gentee a gente no fundo fica com pena de ver a situação da criança e quer ajudar (médico plantonista).

Artmann e River ${ }^{21}$ observam que a possibilidade de vínculo está em relação direta com o acolhimento produzido no serviço desaúde. Apesar da USF ser um serviço que possibilite um maior vínculo com o usuário, o vínculo não é exclusivo à atenção primária.

Os afetos, os processos identificatórios e os aspectos transferenciais e contratransferenciais que podem estar presentes nas relações interpessoais ${ }^{10}$ entre usuários e trabalhadores de saúde podem interferir no vínculo e, consequentemente, na produção do cuidado.

A construção do vínculo, segundo Campos ${ }^{5}$, está estreitamente relacionada à capacidade da equipe responsabilizar-se pela saúde da população, isto é, encarregar-se deseu acompanhamento sistemático e isto não foi observado na USF investigada.

A equipe de saúde da família acha impossível acompanhar a população da área de abrangência pela quantidade de pessoas adscritas (2.911 pessoas), mas também não estabelece nenhuma diferença de atenção a todas as pessoas ou famílias em risco biológico, subjetivo ou social. 0 acesso éviabilizado em função da capacidade deatendimento do serviço e não pela classificação de risco. Os procedimentos administrativos adotados na unidade quase sempre desconsideram a singularização do cuidado.

O modus operandi da equipe de saúde da família com disponibilidade de horários para reunião de equipe, educação permanente e visita domiciliar demonstra um avanço na organização do processo de trabalho na medida em que promoveo planejamento eexecução do trabal ho de forma dialogada, o aprimoramento técnicoprofissional e a apreensão das dimensões psicossociais e culturais do processo saúde-doença na clínica cotidiana. Entretanto, verificamos queainda é prevalente a abordagem individual, prescritiva, apoiada em exames e medicamentos, com consultas médicas agendadas de dez em dez minutos, consultas de enfermagem, consultas de nutrição espelhando um trabalho fragmentado apesar da existência de uma equipe multiprofissional. 0 cuidado não se dá de forma integrada. 
Poucos são os usuários conhecidos e atendidos por toda a equipe de saúde. Os ACS são os trabal hadores de saúde que mais conhecem os sujeitos e a família com risco social e orgânico e o território de abrangência da Unidade de Saúde. Entretanto, é dada, por um lado, pouca relevância para esse conhecimento na produção do cuidado como, por exemplo, não se prioriza a consulta e distribuição de medicação para os portadores de doenças crônicas. Por outro lado, algumas vezes essas informações limitam o contato da equipe com o usuário. A ACS diz que não faz visita à mulher de quem suspeita traficar drogas.

A USF não consegue absorver as demandas dos usuários nas situações agudas e, quando desperta para a baixa cobertura de ações programáticas, tem por hábito fazer atividades "campanhistas".

Por sua vez, existem ranhaduras no vínculo grupal da própria equipe que, certamente, interferem no cuidado ao usuário e no trabalho em equipe. Alguns trabal hadores queixam-se que "a médica não abre espaço, não tem tempo de nos atender. A gente tem que procurar outra unidade para atendimento médico". Também não se sentem atendidos atenciosamente pela enfermagem quando precisam.

0 relato da auxiliar de consultório dentário retrata conflitos ao dizer que "raramente eu participo das reuniões de equipe por que eu não te nho queixa das pessoas e as pessoas não têm queixas de mim".

Enriquez ${ }^{8}$ afirma que em toda organização encontram-se problemas essenciais postos pela instauração do vinculo social. 0 desejo de morte, 0 ataque aos laços (Bion), a função de evitar ou ne gar 0 outro, a apatia destrutiva, assim como, naturalmente, as tentativas de amor mútuo, de investimento positivo.

\section{Considerações finais}

A organização do processo de trabalho da USF observada parecenão promover suficientemente acolhimento, vínculo e responsabilização com os usuários que os favoreçam a buscar 0 atendimento que necessitam na USF.
O usuário é encaminhado para o SE para atendimento das situações agudas, frequentemente, quando não consegue ser incluído na agenda da unidade; é encaminhado para outras USF para pegar remédios padronizados não existentes na própria USF; é encaminhado para fazer exames em outros serviços pela incapacidade da USF dereconhecer uma urgência erealizar o agendamento sem estabelecimento de prioridade. Enfim, as rotinas administrativas acabam por conduzir o usuário para fora do serviço, sem que haja um acompanhamento da sua trajetória no sistema de saúde, diferentemente das recomendações da Estratégia deSaúde da Família, o queé discutido por Dejours ${ }^{10}$ como defasagem entre a organização do trabalho prescrita e a organização do trabalho real.

Acreditamos que, se não houver uma mudança na forma de produzir a assistência na USF, não haverá uma redução da demanda de atendimentos ambulatoriais na emergência hospitalar enem uma produção de cuidado com qualidade eresolutividade.

Cabe também estabelecer uma rede de conversações entre os serviços, promovendo a integração entreel es para que, ao invés de serem concorrentes na prestação de serviços de saúde, os serviços possam ser complementares e viabilizarem a integralidade do cuidado. Para tal, acreditamos que é preciso começar a discussão pela adesão dos trabal hadores ao projeto assistencial da saúde da família e ao trabalho em rede.

A inadequação da formação dos profissionais, sua baixa adesão ao projeto assistencial ea falta de credibilidade neles por parte da população foram identificados como entraves e, certamente, são outros desafios para o SUS.

Esse estudo possibilitou confirmar outros que apontam a densidade tecnológica, a cultura popular e a dificuldade de acesso organizacional e geográfico aos serviços de aten ção primária como fatores que contribuem para a demanda ao SE. Também lançou uma luz para o peso dos microprocessos políticos, intersubjetivos einconscientes no cotidiano do funcionamento dos serviços desaúde, condicionando os limites e possibilidades da produção do cuidado. 


\section{Colaboradores}

DM B trabalhou na concepção edelineamento da pesquisa, análise e interpretação dos dados e na redação do artigo. MCS auxiliou na concepção e delineamento da pesquisa, análise e interpretação dos dados e na revisão da redação final.

\section{Agradecimentos}

Ao Prof. Dr. Francisco Javier Uribe Rivera, por ter contribuído nas discussões do percurso dessa pesquisa.

\section{Referências}

1. Brasil. Ministério da Saúde. Secretaria de Atenção à Saúde. Departamento de Atenção Básica. M anual de Estrutura Física das U nidades Básicas de Saúde. Brasília: M inistério da Saúde; 2006.

2. Brasil. Ministério da Saúde. Secretaria de Atenção á Saúde. Departamento da Atenção Básica. Política Nacional de Atenção Básica. Braślia: M inistério da Saúde; 2006.

3. Brasil. M inistério da Saúde. Portaria n 1.101/GM de 12/06/2002. Estabelece os parâmetros de cobertura assistencial no âmbito do Sistema Único de Saúde (SUS). Diário Oficial da União 2002; 13 jun.

4. Franco TB, M erhy EE. Programa de Saúde da Família (PSF): contradições de um programa destinado à mudança do modelo tecnoassistencial. In: Merhy EE, Miranda Jr. H, Rimoli J, Franco TB, Bueno WS. 0 trabalho em saúde: olhando e experienciando o SUS no cotidiano. $2^{a}$ ed. São Paulo: Hucitec; 2004. p.55-124.

5. Campos GWS. Saúde Paidéia. São Paulo: Hucitec; 2003.

6. Cecílio LCO. Modelos tecno-assistenciais em saúde: da pirâmide ao círculo, uma possibilidade a ser explorada. Cad Saude Publica 1997; 13(3): 469-478.

7. M attos R. Direito, Necessidades de Saúde e Integralidade In: Pinheiro RE, M attos R, organizadores. Construção social da demanda: direito à saúde, trabaIho em equipe, participação e espaços públicos. Rio de Janeiro: CEPESC/UERJ: Abrasco; 2005. p. 33-46.

8. Enriquez E. Vida psíquica e organização. In: M otta $F C P$, Freitas ME, organizadores. Vida psíquica e organização. 2a ed. Rio de Janeiro: FGV; 2000. p. 11-40.

9. Lévy A. Ciências clínicas e organizações sociais. Belo Horizonte: Autêntica/FUM EC; 2001.

10. Dejours C. A banalização da injustiça social. 6a ed. Rio de Janeiro: FGV; 2005.

11. Plastino CA. O quinto rombo: a psicanálise. In: Santos BS, organizador Conhecimento prudente para uma vida decente. São Paulo: Cortez; 2004.

12. Freitas $M E$. A questão do imaginário e a fronteira entre a cultura organizacional e a psicanálise In: Motta FCP, Freitas M E,organizadores. Vida psíquica e organização. 2a ed. Rio de Janeiro: FGV; 2000. p. 41-73.

13. Lancman S, Sznelwar LI, organizadores. Christophe Dejours: da psicopatologia à psicodinâmica do trabaIho. Rio de Janeiro: Fiocruz; Brasília: Paralelo 15; 2004.

14. Sá MC. Em busca de uma porta de saída: os destinos da solidariedade, da cooperação e do cuidado com a vida na porta de entrada de um hospital de emergência [tese].São Paulo (SP): Instituto de Psicologia, Universidade de São Paulo; 2005.

15. Oliveira LH. Cidadãos peregrinos: Os 'usuários' do SUS e os significados de sua demanda a prontos-socorros e hospitais no contexto de um processo de reorientação do modelo assistencial - U ma análise a partir de usuários do SUS no município de Juiz de Fora [tese]. Rio de Janeiro (RJ): Instituto de M edicina Social, Universidade do Estado do Rio de Janeiro; 2004. 
16. Lévy A. A psicossociologia: crise ou renovação? In: $M$ ata $M$ achado MN, Castro EM, Araújo JNG, Roe del S, organizadores. Psicossociologia - análise social e intervenção. Belo Horizonte: Autêntica; 2001. p. 109-120.

17. Santos BS. Pela mão de Alice: o social e o político na pós modernidade. 5a ed. São Paulo: Cortez; 1999.

18. Azevedo C. Sob o domínio da urgência: $O$ trabalho de diretores de hospitais públicos do Rio de Janeiro [tese].São Paulo (SP): Instituto de Psicologia, Universidade de São Paulo; 2005.

19. Pinheiro R. As práticas do cotidiano na relação oferta e demanda dos serviços de saúde: U m campo de estudo e construção da integralidade. In: Pinheiro RE, M attos $R$, organizadores. Os sentidos da integralidade na atenção e no cuidado à saúde. Rio de Janeiro: IM S-UERJ/Abrasco; 2001. p. 65-112.

20. M erhy EE. Em busca do tempo perdido: a micropolítica do trabalho vivo em saúde. In: M erhy EM, Onoko R, organizadores. Agir em Saúde: um desafio para o público. 2aㅡ ed. São Paulo: Hucitec; 2002. p.71-112.

21. Artmann E, Rivera FJU. Humanização no atendimento em saúde e gestão comunicativa. In: Deslandes SF, organizadora. Humanização dos cuidados em saúde: conceitos, dilemas e práticas. Rio de Janeiro: Fiocruz; 2006. p. 205-231.

Artigo apresentado em 07/03/2008

Aprovado em 18/06/2008 